\title{
Decomposition kinetic study, spectroscopic and pyrolytic analyses of Isoberlinia doka and Pinus ponderosa
}

\section{Ayokunle O. Balogun \& Armando G. McDonald}

Biomass Conversion and Biorefinery Processing of Biogenic Material for Energy and Chemistry

ISSN 2190-6815

Biomass Conv. Bioref.

DOI 10.1007/s13399-015-0185-3

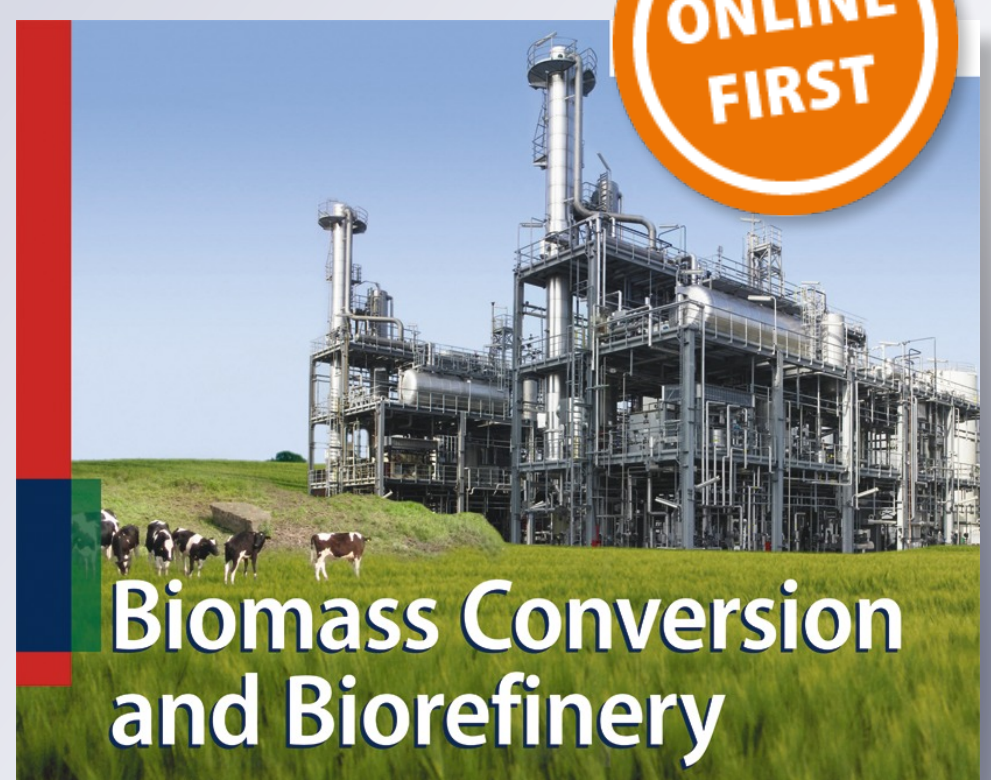

Processing of Biogenic Material for Energy and Chemistry

\section{Springer}

\section{包 Springer}


Your article is protected by copyright and all rights are held exclusively by SpringerVerlag Berlin Heidelberg. This e-offprint is for personal use only and shall not be selfarchived in electronic repositories. If you wish to self-archive your article, please use the accepted manuscript version for posting on your own website. You may further deposit the accepted manuscript version in any repository, provided it is only made publicly available 12 months after official publication or later and provided acknowledgement is given to the original source of publication and a link is inserted to the published article on Springer's website. The link must be accompanied by the following text: "The final publication is available at link.springer.com". 


\title{
Decomposition kinetic study, spectroscopic and pyrolytic analyses of Isoberlinia doka and Pinus ponderosa
}

\author{
Ayokunle O. Balogun ${ }^{1}$ - Armando G. McDonald ${ }^{2}$
}

Received: 16 July 2015 / Revised: 27 August 2015 / Accepted: 29 August 2015

(C) Springer-Verlag Berlin Heidelberg 2015

\begin{abstract}
Two woody species of different origins were subjected to Fourier transform infrared (FTIR) spectroscopy, thermogravimetric analysis, and analytical pyrolysis gas chromatography/mass spectrometry (Py-GC/MS). FlynnWall-Ozawa, a model-free technique, was adopted for the decomposition kinetic study of Isoberlinia doka (ID) and Pinus ponderosa (PP). FTIR spectroscopy was employed to determine the level of cellulose crystallinity in the samples under investigation using the total crystallinity and lateral order indices methods. The apparent activation energy appeared as a function of conversion with significant influence from biomass diversity. The apparent activation energy recorded values of 202 to $365 \mathrm{~kJ} \mathrm{~mol}^{-1}$ for ID and 205 to $583 \mathrm{~kJ} \mathrm{~mol}^{-1}$ for PP. Thus, biomass decomposition kinetics is better modeled as a multi-step reaction mechanism. The analytical Py-GC/MS showed the presence of acids, sugars, and phenolic compounds in significant proportions for the two biomass samples. There were marked distinctions in both the quantity and the individual compounds detected in the biomass samples that were investigated.
\end{abstract}

Keywords FTIR spectroscopy • Thermogravimetric analysis · Kinetic study $\cdot$ Biomass $\cdot$ Analytical Py-GC/MS

Ayokunle O. Balogun

ayokunle.balogun@elizade.university.edu.ng

1 Department of Mechanical Engineering, Faculty of Engineering, Elizade University, P.M.B. 002, Ilara-Mokin, Ondo State, Nigeria

2 Department of Forest, Rangeland and Fire Science, University of Idaho, Moscow, ID 83844-1132, USA

\section{Introduction}

The apparent threat to respective regional energy security provoked by perpetual uncertainty in the international oil market has occasioned sustained global interest in renewable energy resources. The dire environmental consequences and nonsustainability of fossil energy sources have also been major catalysts in the quest for alternative energy among policy makers and researchers worldwide. Biomass resources, alternative energy sources, have received considerable attention because they are abundantly available at relatively inexpensive cost. They also have a reputation of low carbon footprint and a wide geographical spread.

Biomass can be broadly classified into woody plants, herbaceous plants and grasses, aquatic plants, and manure [1]. Isoberlinia doka (ID) and Pinus ponderosa (PP) are examples of important woody species that have significant socioeconomic and ecological value in their individual geographical regions. In West Africa, for instance, an estimate of 2.6× $10^{6} \mathrm{~km}^{2}$ has been reported to be occupied by the Isoberlinia woodlands [2]. Fuel wood or charcoal production, furniture making, structural purpose, craftwork, and light construction are some of the numerous applications of ID. Similarly, PP thrives over a vast expanse of land (approximately $11 \times$ $10^{10} \mathrm{~m}^{2}$ ), occupying more than $35 \%$ of land area in the USA [3, 4]. The annual production of PP is reported to rank third in volume after Douglas fir and Hem fir (Western hemlock, grand fir, white fir, Pacific silver fir, and California red fir); however, PP was second in total value. Among other softwood species, PP possesses an exceptional dimensional stability and finds useful applications in residential construction, paneling, and various cabinet works. Apparently, wood processing activities generate significant wastes $(35 \% \mathrm{w} / \mathrm{w}$ from original $\log$ ), which oftentimes pose daunting management challenges. This is particularly so in the developing 
nations, thus, making them attractive feedstocks in bioenergy application, biofuel production, and the chemical extraction industry [5].

Woody biomass is heterogeneous in nature and possesses a complex chemical character. Its cell wall composition is an intricate matrix of carbohydrates (cellulose and hemicellulose) and lignin alongside low molecular weight organics, usually referred to as extractives. Cellulose is a linear polymer that comprises largely inter- and intramolecular glucosidic bonds, forming an ordered crystalline macromolecule. A proportion of cellulose is also amorphous in nature as exemplified by about $35 \%$ lack of crystallinity in wood-derived cellulose [6]. The degree of polymerization of cellulose is another critical aspect of its structure, and it is estimated to be between 1000 and 15,000 [6]. Hemicellulose, though much less orderly, contributes significantly to the structural integrity of the plant cell wall $[7,8]$. It is a highly branched carbohydrate noted for its cross-linking effect [8]. The degree of polymerization exhibited by hemicellulose is much lower than that found in cellulose, typically between 100 and 200 [6]. Lignin is primarily responsible for the structural rigidity of the cells. Its chemical structure is essentially aromatic in nature, interconnected by ether and carbon-carbon linkages [9].

Since woody biomass possesses numerous constituents with diverse chemical composition, preliminary biomass characterization becomes a research priority in most bioenergy application programs. Aside from the traditional chemical and thermal analysis, spectroscopic method is another valuable analytical tool sensitive to structural features. The former is an invasive and a destructive technique; however, infrared spectroscopy has the merit of non-destructive capability while providing both qualitative and semi-quantitative information. Several comparative investigations have employed Fourier transform infrared spectroscopy (FTIR) for the analysis of different wood species. Popescu et al. [10] deployed the FTIR technique to study the structural differences between a hardwood and a softwood species. A similar means was used by Rosu et al. [11] to investigate the chemical and structural changes on a wood surface due to a photo-degradation process. Balogun et al. [12] conducted an FTIR study of a woody and non-woody biomass resource while Huang et al. [13] undertook an IR spectroscopic study on the distinction of three different types of wood species.

Evidently, thermochemical decomposition processes play a critical role in the utilization of lignocellulosic biomass for renewable energy programs. During biomass decomposition, diverse organic species are evolved at different rates due to the heterogeneity inherently associated with lignocellulosic biomass. The development of accurate decomposition mechanisms and the design of optimum process conditions and efficient thermal reactors are therefore major research goals which can be accomplished through the study of biomass decomposition kinetics. In the study of biomass decomposition kinetics, the rate of reaction is an important consideration as it proceeds uniquely as a function of process temperature, heating rate, and pressure [14]. The evaluation of kinetic variables can be done by either model-fitting or modelfree techniques. However, model-free techniques have some distinct merits that have been earlier reported in a previous publication [15].

In addition, thermochemical decomposition processes such as pyrolysis are designed primarily for the extraction of bio-oil. The application of the bio-oil is largely dependent on its chemical composition; thus, the identification of the individual chemical species is of prime importance to researchers. The analytical pyrolysis gas chromatography/mass spectrometry (Py-GC/MS) is a powerful tool that may be deployed for prospecting the broad spectrum of chemical compounds in bio-oil [15]. Balogun et al. [16] carried out a Py-GC/MS experiment on biomass species of both woody and non-woody origin.

The aims of this study were to provide information on the suitability of a temperate region wood species, Pinus ponderosa $(\mathrm{PP})$, and a tropical wood species, Isoberlinia doka (ID), as a pyrolysis feedstock. The Flynn-Wall-Ozawa (FWO) method, a model-free technique, was chosen for the determination of the kinetic variables of thermal degradation by TGA. The physical and chemical compositions of the samples were determined by classical methods and FTIR spectroscopy. Analytical pyrolysis (Py-GC/MS) was performed to determine the pyrolysis products that could be formed from these different species.

\section{Experimental}

\subsection{Sample preparation}

The ID sample was obtained from an Ilorin timber processing plant, Kwara state, Nigeria [12]. The PP sample was sourced from Bennett Lumber, Princeton, Idaho. The two biomass samples were milled in a Thomas Wiley mill model 4 $(1 \mathrm{~mm}$ screen) and screened to obtain a particle size between 0.5 and $1.0 \mathrm{~mm}$.

\subsection{Compositional analysis}

The dichloromethane $\left(\mathrm{CH}_{2} \mathrm{Cl}_{2}\right)$ extractives content was determined, in duplicate, according to ASTM method D 1108 as detailed by Balogun et al. [16]. The carbohydrate analysis was determined using a modified sulfuric acid method for cellulosic samples [17]. Briefly, extractives-free wood $(10 \mathrm{mg})$ was weighed into a glass tube to which $77 \% \mathrm{H}_{2} \mathrm{SO}_{4}(100 \mu \mathrm{L})$ was added and mixed for $5 \mathrm{~min}$. Then $5 \%$ phenol in water $(1 \mathrm{~mL})$ plus conc. $\mathrm{H}_{2} \mathrm{SO}_{4}(5 \mathrm{~mL})$ were added to the mixture, vortex mixed, incubated at $30{ }^{\circ} \mathrm{C}$ for $30 \mathrm{~min}$, and absorbance measured at $490 \mathrm{~nm}$ (Biomate; Thermo Electron Corp.). The lignin 
content was determined, in duplicate, according to the acetyl bromide procedure by Liyama and Wallis [18]. Concisely, extractives-free biomass $(5 \mathrm{mg})$ was placed in a glass tube to which $25 \%(w / w)$ acetyl bromide in acetic acid $(5 \mathrm{~mL})$ containing perchloric acid $(70 \%, 0.2 \mathrm{~mL})$ was added and heated to $70{ }^{\circ} \mathrm{C}$ for $30 \mathrm{~min}$. The solution was then transferred to a $100-\mathrm{mL}$ volumetric flask containing $2 \mathrm{M} \mathrm{NaOH}(10 \mathrm{~mL})$ and acetic acid $(25 \mathrm{~mL})$, the volume made up with acetic acid, and absorbance measured at $280 \mathrm{~nm}$ (Biomate; Thermo Electron Corp). The absorptivity of lignin $(\varepsilon)$ values of 23.3 and $20.9 \mathrm{~L} \mathrm{~g}^{-1} \mathrm{~cm}^{-1}$ were used for PP and ID, respectively [18]. The ash content was determined by furnacing samples at $600{ }^{\circ} \mathrm{C}$ according to ASTM D 1102. The proximate analysis (ash content, fixed carbon (FC), and volatile matter (VM)) of these samples was performed according to ASTM E870.

\subsection{FTIR spectroscopy}

Spectroscopic analysis of vacuum-dried biomass samples were performed on an iS5 spectrometer (ThermoScientific). Two spectra were collected in the single bounce attenuated total reflection (ATR) mode (iD5, $\mathrm{ZnSe}$ ) in the scan region of 650 to $4000 \mathrm{~cm}^{-1}$ and a total of 64 scans. An average spectrum was generated and subsequently ATR and baseline corrected mathematically with the OMNIC v9 software.

\subsection{Higher heating value (HHV) determination}

The HHV for pressed dried samples $(5.5 \times 6.3 \mathrm{~mm} \varnothing)$ were determined, in duplicate, by bomb calorimetry (Model 1261; Parr Instruments) according to ASTM D 5865. The determination of the HHV was also estimated using the mathematical model developed by Shafizadeh and Degroot [19]. The model correlates carbohydrate, lignin, and extractives contents according to Eq. (1)

$\mathrm{HHV}=0.1739(C e)+0.2663(L)+0.3219(E)$

where $C e$ is carbohydrate, $L$ is lignin, and $E$ is extractives content.

\subsection{Biomass decomposition kinetics}

The global kinetic model for the rate of biomass decomposition is expressed as

$\frac{d \theta}{d t}=A \exp \left(-\frac{E}{R T}\right) f(\theta)$

integrating Eq. (2) by separation of variables at constant heating rate $\beta$ yields

$g(\theta)=\frac{A}{\beta} \int_{T_{0}}^{T} \exp \left(-\frac{E}{R T}\right) d T=\left(\frac{A E}{\beta R}\right) p(x)$ where $A\left(\mathrm{~min}^{-1}\right)$ is the pre-frequency factor, $R$ is the universal gas constant $\left(8.314 \mathrm{~J} \mathrm{~mol}^{-1} \mathrm{~K}^{-1}\right), \theta$ is the degree of conversion, and $f(\theta)$ is the reaction model which is a function of conversion. The term $p(x)$ represents the temperature integral and has no exact analytical solution. The approximation proposed by FWO is commonly used for the linearization of the temperature integral in Eq. (3). A detailed derivation is presented in a previous publication [15].

\subsection{Analytical Py-GC/MS and TGA experiments}

Analytical Py-GC/MS was conducted, in duplicate, on a Pyrojector II (SGE Analytical Science) at $500{ }^{\circ} \mathrm{C}$ in $\mathrm{He}$ coupled to a GC/MS (FOCUS-ISQ; ThermoScientific) instrument operating in the electron impact ionization mode. The compounds were separated on the ZB5-MS capillary column $(30 \times 0.25 \mathrm{~mm} \varnothing$; Phenomenex $)$ with temperature programmed to be 40 to $250{ }^{\circ} \mathrm{C}$ at $5 \mathrm{~K} \mathrm{~min}^{-1}$. The eluted compounds were identified by their mass spectra, authentic standards, and with the NIST 2008 library matching. TGA was performed on a Perkin Elmer TGA-7 instrument from 50 to $900{ }^{\circ} \mathrm{C}$ at heating rates of 5,10 , and $15 \mathrm{~K} \mathrm{~min}^{-1}$ under nitrogen $\left(30 \mathrm{~mL} \mathrm{~min}^{-1}\right)$, and data analyzed using the Pyris v8 software (Perkin Elmer) as detailed by Balogun et al. [15].

\section{Results and discussion}

\subsection{Compositional and proximate analyses}

The cell wall structure for woody biomass is primarily a composite of polysaccharides and lignin, and the amounts of these components vary from one woody species to another. The compositional and proximate analyses of the biomass samples being studied is presented in Table 1. It is shown that the extractive content of ID $(0.58 \%)$ is much lower than that of PP (5.1\%). The PP value for $\mathrm{CH}_{2} \mathrm{Cl}_{2}$ extractives content was consistent with the literature (3.8-6.1\%) [20, 21]. The carbohydrate content for both (ID and PP) samples are comparably close and the PP value is slightly lower than reported by Soria et al. [21].

The $\mathrm{CH}_{2} \mathrm{Cl}_{2}$ extractives content for ID agrees with values from literature for some African tropical woods (Lophira alata Banks ex Gaertn. f, Aucoumea klaineana Pierre, Microberlinia brazzavillensis A. Chev), all with values less than $1 \%$ [22]. The lignin content of ID (a tropical hardwood) is relatively higher than that of PP (softwood). The lignin content of PP was comparable to literature Klason lignin values [20, 21]. Telmo and Lousada [23] observed a similar trend in which the values for the Klason lignin content of some tropical hardwood species were greater than those of the softwood species. 
Table 1 Proximate and compositional analyses of woody biomass samples

\begin{tabular}{|c|c|c|c|c|c|c|c|c|}
\hline \multirow[t]{2}{*}{ Biomass } & \multicolumn{3}{|c|}{ Compositional analysis $^{\mathrm{a}}$ (wt.\%) } & \multicolumn{3}{|c|}{ Proximate analysis ${ }^{\mathrm{b}}$ (wt.\%) } & \multirow[t]{2}{*}{$\mathrm{HHV}^{\mathrm{b}, \mathrm{c}}\left(\mathrm{MJ} \mathrm{kg}^{-1}\right)$} & \multirow[t]{2}{*}{$\mathrm{HHV}^{\mathrm{b}, \mathrm{d}}\left(\mathrm{MJ} \mathrm{kg}^{-1}\right)$} \\
\hline & $\mathrm{CH}_{2} \mathrm{Cl}_{2}$ extractives & Total carbohydrate & Lignin & Ash & Fixed carbon & Volatile matter & & \\
\hline ID & 0.6 & 55.4 & 33.9 & 2.7 & 16.9 & 80.8 & 20.1 & 18.9 \\
\hline PP & 5.1 & 54.7 & 29.3 & 0.3 & 6.4 & 93.4 & 20.4 & 19.0 \\
\hline
\end{tabular}

${ }^{a}$ Dry-ash-free basis

${ }^{\mathrm{b}}$ Dry basis

${ }^{\mathrm{c}}$ Bomb calorimetry

${ }^{\mathrm{d}}$ Mathematical model

The values for the ash content obtained for both biomass samples are in agreement with values in literature [16, 24]. However, it is noteworthy that the ash content for PP $(0.29 \%)$ is much lower than the value obtained for ID (2.72\%).

Since ash is typically composed of inorganic minerals, the variation observed may be explained by the differing climatic and environmental conditions in the respective geographical regions. Das et al. [25] observed that ash in biomass has significant influence on the quality of organic yield. Hence, biomass resources with relatively lower ash content may be more attractive feedstock in pyrolytic reaction processes. The ID and PP values obtained for the volatile matter and fixed carbon contents are well within the range specified in literature for woody species $[16,24]$. The volatile matter/fixed carbon ratio also conforms to findings from previous publications [24]. Generally, biomass is known to possess much higher volatile matter content than solid fossil fuels like coal and peat, making it more suitable for pyrolytic oil production. In Table 1, the two methods used for the HHV determination showed small variations in the values obtained for both samples. This notwithstanding, the trend for the HHV was fairly similar as PP had a slightly higher HHV in both cases. The HHV for both samples under investigation are close and fall within the range for some woody species $[12,23]$.

\subsection{FTIR spectroscopy of woody biomass}

The biomass cell wall is a complex macromolecular configuration of polymer fractions which differ from one lignocellulosic biomass to the other. FTIR spectroscopy is a viable analytical tool for the examination of the chemical composition and functional groups of lignocellulosic material. The FTIR spectra of ID and PP are shown in Fig. 1. But for few exceptions, these spectra have essentially similar features. In the band region of $3600-3000 \mathrm{~cm}^{-1}$, ID and PP show peaks that are characteristic of $\mathrm{OH}$ bond vibrations in hydroxyl groups at 3344 and $3346 \mathrm{~cm}^{-1}$, respectively $[12,26]$. At 2900$2700 \mathrm{~cm}^{-1}$, both samples display prominent absorption peaks, which are attributable to asymmetric methoxyl C-H stretching vibrations [10].
The degree of cellulose crystallinity is a vital piece of information that can be obtained from some specific spectral bands on the FTIR spectrum. Bands assigned to cellulose were $897 \mathrm{~cm}^{-1}\left(\mathrm{C}_{1}-\mathrm{O}-\mathrm{C}_{4}\right.$ glycosidic linkage), $1370 \mathrm{~cm}^{-1}$ (C-H bending), $1420 \mathrm{~cm}^{-1}$ (C-H wagging), and $2900 \mathrm{~cm}^{-1}$ (C-H stretching) [27, 28]. The overlapping bands (1335 and $1315 \mathrm{~cm}^{-1}$ ) observed on the IR spectrum for PP is an indication of cellulose with a relatively high crystalline cellulose I content $[12,29]$. The intense peak at $1030 \mathrm{~cm}^{-1}$ is attributable to $\mathrm{C}-\mathrm{OH}$ and $\mathrm{O}-\mathrm{CH}_{3}$ stretching vibrations, and they are characteristic bands of lignin and cellulose fractions [26]. Furthermore, the band at $1157 \mathrm{~cm}^{-1}$ is characteristic of cellulose $\mathrm{C}-\mathrm{O}-\mathrm{C}$ bridges of amorphous cellulose. Cellulose crystallinity was determined using two FTIR methods, the lateral order index (LOI) and total crystallinity index (TCI) [30-32]. The intensity ratios at $1420 \mathrm{~cm}$ and $897 \mathrm{~cm}^{-1}\left(\mathrm{I}_{1420} / \mathrm{I}_{897}\right)$ was used to determine the cellulose crystallinity by LOI and gave values of 1.7 and 1.5, respectively, for ID and PP. The LOI values were consistent with hardwoods ( $\mathrm{LOI}=1.6$ ) [29]. Furthermore, the TCI was determined from the band ratios at 1370 and $2900 \mathrm{~cm}^{-1}\left(\mathrm{I}_{1370} / \mathrm{I}_{2900}\right)$, and values of 0.55 for ID and 0.70 for PP were obtained. These TCI values were lower than values obtained from softwood and hardwood pulps [31].

The characteristic lignin bands at 1605 and $1508 \mathrm{~cm}^{-1}$ (aromatic rings), $1462 \mathrm{~cm}^{-1}$ (C-H deformation), $1330 \mathrm{~cm}^{-1}$ (S ring breaking for ID), and $1270 \mathrm{~cm}^{-1}\left(\mathrm{OCH}_{3}, \mathrm{G}\right.$ ring breaking) were observed in the spectra of ID and PP. The lignin syringyl/ guaiacyl $(\mathrm{S} / \mathrm{G}=1.1)$ ratio for ID was calculated from 1462 to $1508 \mathrm{~cm}^{-1}$ band intensity ratios [33] and was lower than other hardwoods (S/G 1.2-2.0) [34, 35].

\subsection{Thermal decomposition}

The data obtained from the TGA are expressed as a function of conversion $(\theta)$ according to Eq. (4):

$\theta=\frac{m_{i}-m}{m_{i}-m_{f}}$ 
Fig. 1 FTIR spectra of ID and PP woody biomass

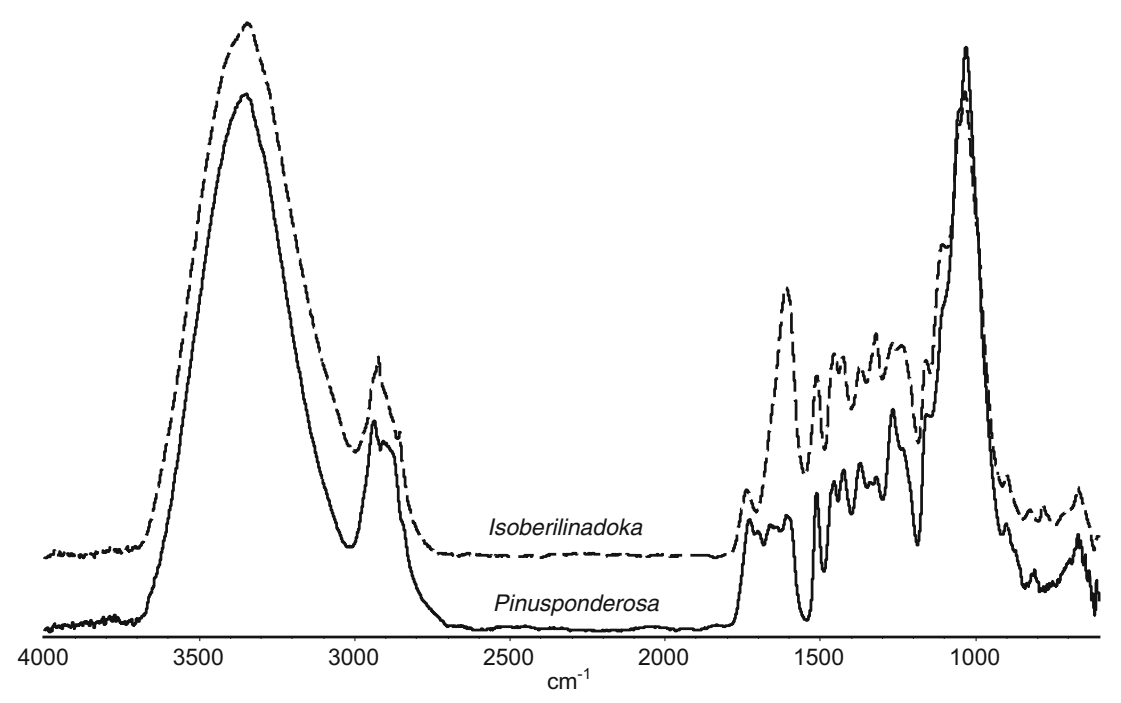

where $m_{i}$ is the initial mass of the sample, $m$ is the mass of the decomposed sample, and $m_{f}$ is the mass of the final residue. The thermal decomposition profiles obtained for PP and ID at multiple heating rates are shown in Fig. 2, and this degradation behavior is typical of most lignocellulosic biomass [7, 16]. The small DTG peaks below $350 \mathrm{~K}$ indicate the evaporation of moisture and the liberation of some low molar mass organics. The appearance of broad DTG peaks between 500 and $650 \mathrm{~K}$, where the highest level of volatile release is recorded, represents primarily the decomposition of the carbohydrate (hemicellulose and cellulose) fraction. It is noteworthy that the over $50 \%$ of mass loss experienced at this stage agrees with the values obtained for the carbohydrate content in Table 1. The hemicellulose decomposition usually precedes with a characteristic shoulder, while the contiguous peaks are traditionally assigned to cellulose decomposition [36]. The gradual slope above $650 \mathrm{~K}$ is representative of lignin decomposition as lignin is considered to degrade over a wide temperature range [36]. However, the sharp peaks around $700 \mathrm{~K}$ might be on account of some heavy chemical species formed from subsequent secondary reactions [37].

Figure 2 also illustrates the influence of varied heating rates on the thermal decomposition process. It is observed that an increase in the heating rate shifts both the onset of decomposition and the DTG peaks toward higher temperature values without changes in the thermal profiles. Based on the knowledge of reaction kinetics, this thermal decomposition trend underscores the temperature dependence of the reaction rate and the fact that the decomposition mechanism is independent of the heating rate particularly under the experimental conditions deployed [14]. Similarly, the height of the derivative peaks increases as the heating rate rises.

\subsection{Biomass reaction kinetics}

The plot of the apparent activation energy, $\mathrm{E}(\theta)$, versus $\theta$, obtained using the FWO model for ID and PP is displayed in Fig. 3, showing values in the $0.02 \leq \theta \geq 0.98$ domain with 0.02 intervals. The dependence of activation energy on the extent of conversion is clearly evident as $\mathrm{E}(\theta)$ varies continuously throughout the conversion range. This is not an
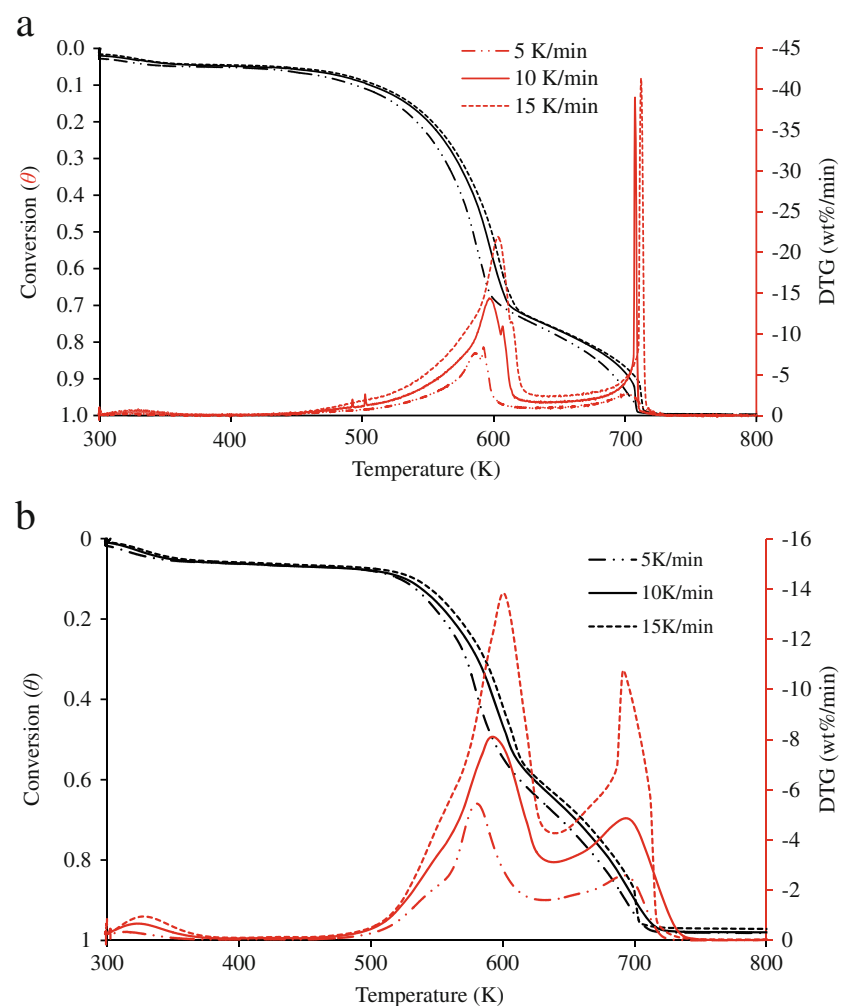

Fig. 2 TGA and DTG curves at 5, 10, and $15 \mathrm{~K} \mathrm{~min}^{-1}$ for a Pinus ponderosa (PP) and $\mathbf{b}$ Isoberlinia doka (ID) thermal decomposition 


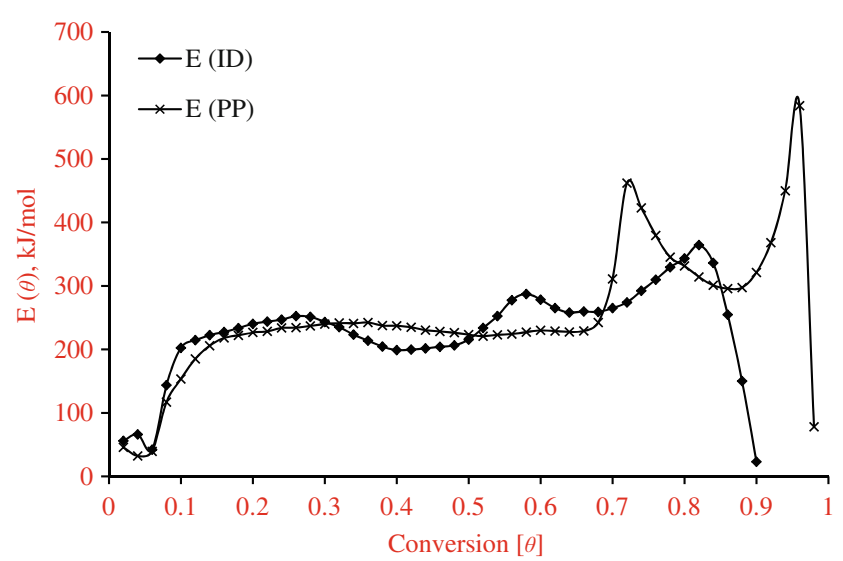

Fig. 3 Apparent activation energy, $\mathrm{E}(\theta)$, as a function of degree of $\theta$ for ID and PP samples

uncommon phenomenon as biomass decomposition mechanisms are often fraught with successive and concurrent reaction routes. More so, the heterogeneous character of lignocellulosic biomass makes biomass thermal degradation highly susceptible to competing reactions. The values of $\mathrm{E}(\theta)$ obtained for both PP and ID samples also show significant variation as $\theta$ progresses. The diversities in the structural and chemical makeup of the polymeric fractions for the two woody species are likely to be contributory.

The early stage of the decomposition process $(\theta<0.1)$ recorded average values of 54 and $40 \mathrm{~kJ} \mathrm{~mol}^{-1}$ for ID and PP, respectively. These values are relatively higher than that reported in literature for a woody biomass at the dehydration stage [38]. Lopez-Velaquez et al. [14] also observed that the $\mathrm{E}(\theta)$ values obtained at the dehydration stage were much higher than the water diffusion energy barrier required to weaken the van der Waals bonds. This apparent contradiction can be explained by the inability of chemical kinetic models to accurately describe dehydration, a physical process, which is predominant at the early stage of most biomass thermochemical processes.

The $\mathrm{E}(\theta)$ values rose above $200 \mathrm{~kJ} \mathrm{~mol}^{-1}$ at $\theta \geq 0.1$. These values are typical of $\mathrm{E}(\theta)$ for woody biomass above $10 \%$ conversion level $[15,39]$. Figure 3 shows a slow rise in $\mathrm{E}(\theta)$ values till they peak at 242 (PP) and $251 \mathrm{~kJ} \mathrm{~mol}^{-1}$ (ID) as $\theta$ changes from 0.14 to 0.36 for PP and 0.10 to 0.28 for ID. This stretch corresponds to the region assigned principally to hemicellulose decomposition. The exhibition of the gentle slopes might not be unconnected with the fact that hemicellulose is a composite of numerous polysaccharides with its characteristic non-crystallinity, thereby making it easily prone to chain cleavage along the weak bonds [14]. It has been reported that the decomposition of hemicellulose is usually accompanied with the formation of polymeric intermediates that undergo secondary thermal cracking $[9,14]$. This may have led to the peak $\mathrm{E}(\theta)$ value at the final stage of hemicellulose decomposition. Contrary to a fairly constant $\mathrm{E}(\theta)$ value observed for PP as $\theta$ progresses to about 0.7 , a sudden reduction in the value of $\mathrm{E}(\theta)$ is noted for ID $\left(199 \mathrm{~kJ} \mathrm{~mol}^{-1}\right)$ at $\theta=0.4$ followed by an essentially constant $\mathrm{E}(\theta)$ to around $\theta=0.5$. This trend may be an emphasis on the diverse nature of polymer components or their distribution as it relates to different biomass species [9]. Furthermore, the dependence of $\mathrm{E}(\theta)$ on $\theta$ is again demonstrated around the cellulose decomposition region. This behavior in ID may be according to a conclusion that bond rupture happens during cellulose decomposition at the point of maximum strain in the polymeric configuration, possibly along the boundaries between the amorphous and crystalline region of cellulose $[9,14]$. The occurrence of the primary prominent peaks at $\theta=0.58$ (ID) and 0.72 (PP) may have arisen from the simultaneous contribution of each biomass fraction and the associated cross-linking effect, accentuating the competitive character of biomass decomposition processes [40]. Lastly, at $\theta=0.82$ and 0.96 , maximum values for $\mathrm{E}(\theta)$ read 364 and $583 \mathrm{~kJ} \mathrm{~mol}^{-1}$ for ID and PP, respectively. This final stage represents lignin decomposition on one hand and the degradation of residual species formed from series of secondary reactions on the other. In summary, this is a lucid demonstration of the intricacies involved with biomass decomposition processes in which each biomass fraction possesses definite reaction characteristics. Biomass thermal decomposition processes are more accurately modeled as multi-step reaction mechanisms characterized by multiple reactions occurring along parallel and successive pathways. This conclusion agrees with findings from literature [12, 14].

\subsection{Analytical Py-GC/MS experiments}

The thermal decomposition processes of lignocellulosic materials are known to evolve volatiles that consist of numerous chemical species. The volatiles emerge as a result of thermal cracking of polymeric components, that is, hemicellulose, cellulose, and lignin. The Py-GC/MS is a powerful analytical tool, which is valuable in prospecting the chemical constituents in the thermal decomposition process, pyrolysis, of most biomass resources. Table 2 shows the volatile pyrolysis compounds from PP and ID, their respective retention time, molecular ion, and percent peak area.

A total of 51 compounds were detected during the PyGC/MS analysis of PP and ID. Aside from the following compounds [(i) furfuran, (ii) 2-hydroxy-cyclopent-2-ene1-one, (iii) 2-hydroxy-3-methyl-2-cyclopenten-1-one, (iv) isoeugenol, (v) 2 propenal guaiacol], which have yields that are fairly similar for both feedstock, significant differences were observed in the percent peak area for other compounds. For instance, ID had a relatively higher yield of ethyl guaiacol, vinyl guaiacol (products of lignin decomposition), and levoglucosan. At a relatively low temperature $\left(\leq 300{ }^{\circ} \mathrm{C}\right)$, levoglucosan, an intermediate product, is formed during the thermal gradation of cellulose as 
Table 2 Analytical Py-GC/MS of ID and PP showing retention time, molecular ion, compounds, and \% peak area

\begin{tabular}{|c|c|c|c|c|}
\hline Compound & $\mathrm{M}^{+}$ & RT (min) & $\begin{array}{l}\text { PP } \\
\% \text { Area peak }\end{array}$ & ID \\
\hline $\mathrm{CO}_{2}$ & 44 & 1.54 & 4.6 & 7.6 \\
\hline Furfuran & 68 & 1.76 & 2.2 & 2.2 \\
\hline Acetic acid & 60 & 2.26 & 2.7 & 3.4 \\
\hline 1-Hydroxy-2-propanone & 74 & 2.57 & 2.0 & 1.5 \\
\hline Methyl pyruvate & 102 & 3.81 & 1.5 & 1.1 \\
\hline Butanedial & 86 & 4.01 & 0.5 & - \\
\hline Acetic anhydride & 102 & 4.15 & 1.3 & - \\
\hline Furaldehyde & 96 & 5.00 & 0.9 & 1.0 \\
\hline 3-Methyl-penta-1,3-diene-5-ol & 98 & 5.52 & 0.5 & 0.6 \\
\hline 5-Methyl-furanone & 98 & 5.78 & 0.3 & 0.5 \\
\hline 2(5H)-Furanone & 84 & 6.94 & 0.6 & - \\
\hline Cyclohexen-3-ol & 98 & 7.08 & 0.2 & - \\
\hline 2-Hydroxy-cyclopent-2-ene-1-one & 98 & 7.27 & 1.7 & 1.6 \\
\hline Benzaldehyde & 106 & 8.22 & 0.4 & - \\
\hline 2-Methyl-2-cyclohexene-1-ol & 110 & 8.63 & 0.3 & - \\
\hline$\alpha$-Pinene & 136 & 9.00 & 0.3 & - \\
\hline 3,4-dihydro-2-methoxy-2H-pyran & 114 & 9.24 & 0.9 & 0.7 \\
\hline$\beta$-Pinene & 136 & 9.55 & 0.6 & - \\
\hline 2H-pyran-2,6(3H)-dione & 112 & 9.68 & 0.3 & - \\
\hline 2-Hydroxy-3-methyl-2-cyclopenten-1-one & 112 & 10.09 & 1.0 & 1.0 \\
\hline Methyl phenol & 108 & 10.90 & 0.2 & - \\
\hline Methyl phenol & 108 & 11.52 & 0.5 & - \\
\hline Guaiacol & 124 & 11.87 & 3.0 & 3.9 \\
\hline Non-2-en-1-ol & 142 & 14.71 & 1.4 & 0.9 \\
\hline Methyl guaiacol & 138 & 14.86 & 6.3 & 4.6 \\
\hline 5-Hydroxymethyl-2-furaldehyde & 126 & 16.01 & 1.6 & - \\
\hline Ethyl guaiacol & 152 & 17.21 & 1.4 & 2.1 \\
\hline Vinyl guaiacol & 150 & 18.19 & 5.2 & 7.3 \\
\hline Syringol & 154 & 19.14 & - & 2.9 \\
\hline Eugenol & 164 & 19.33 & 2.6 & 1.8 \\
\hline Propyl guaiacol & 166 & 19.56 & 0.4 & 0.6 \\
\hline Vanillin & 152 & 20.45 & 1.9 & 1.1 \\
\hline cis-Isoeugenol & 164 & 20.63 & 1.4 & 1.3 \\
\hline Methyl-syringol & 168 & 21.61 & - & 3.2 \\
\hline trans-Isoeugenol & 164 & 21.70 & 6.4 & 6.9 \\
\hline Propyl guaiacol & 166 & 21.94 & 0.8 & 1.0 \\
\hline 1,2-Dipropenyl guaiacol & 162 & 22.36 & 1.1 & 0.6 \\
\hline Acetoguaiacone & 166 & 22.63 & 1.0 & 1.7 \\
\hline Ethyl syringol & 182 & 23.54 & - & 1.1 \\
\hline Guaiacyl acetone & 180 & 23.69 & 1.3 & 0.5 \\
\hline Levoglucosan & 162 & $22-24$ & 6.1 & 8.8 \\
\hline 4-Vinyl-syringol & 180 & 24.46 & - & 5.4 \\
\hline Coniferyl alcohol & 180 & 24.71 & 0.7 & 0.5 \\
\hline Unknown & 180 & 24.9 & 0.6 & - \\
\hline 4-Allyl-syringol & 194 & 25.34 & - & 1.3 \\
\hline Guaiacyl acetic acid & 182 & 26.43 & 2.1 & - \\
\hline 2-Propenyl syringol & 194 & 26.63 & - & 1.8 \\
\hline Coniferyl alcohol & 180 & 26.96 & 1.5 & - \\
\hline
\end{tabular}


Table 2 (continued)

\begin{tabular}{|c|c|c|c|c|}
\hline Compound & $\mathrm{M}^{+}$ & $\mathrm{RT}(\min )$ & $\begin{array}{l}\text { PP } \\
\% \text { Area peak }\end{array}$ & ID \\
\hline Syringaldehyde & 182 & 27 & - & 1.1 \\
\hline 1,2-Dipropenyl syringol & 192 & 27.18 & - & 1.3 \\
\hline 2-Propenyl syringol & 194 & 27.55 & - & 5.7 \\
\hline Acetosyringone & 196 & 28.26 & - & 3.6 \\
\hline 2-Propenal guaiacol & 178 & 28.33 & 3.0 & 2.6 \\
\hline 3-Hydroxy-1-propenyl-guaiacol & 180 & 28.53 & 12.0 & - \\
\hline Syringyl acetone & 210 & 29.05 & - & 1.0 \\
\hline Hexadecanoic acid & 256 & 32.86 & 4.0 & 1.3 \\
\hline Sinapyl aldehyde & 208 & 33.27 & - & 1.8 \\
\hline Sinapyl alcohol & 210 & 33.47 & - & 1.0 \\
\hline Resin acid & 256 & 34.1 & 1.0 & - \\
\hline Methoxy-hydroxy-stillbene & 226 & 34.61 & 2.1 & - \\
\hline Resin acid & 256 & 34.99 & 1.0 & - \\
\hline Oleic acid & 282 & 36.14 & 4.1 & - \\
\hline Resin acid & 254 & 37.21 & 0.6 & - \\
\hline Dimethoxy stillbene & 240 & 37.8 & 2.1 & - \\
\hline Total & & & 100.0 & 100.0 \\
\hline
\end{tabular}

a result of depolymerization reaction [41]. The slightly higher value of carbohydrate observed in Table 1 for ID may be responsible for the relatively higher yield of levoglucosan in ID. A similar trend had been noted in literature, in which a woody species with the higher glucose content produced the largest quantity of levoglucosan [41]. Further reaction of levoglucosan through fission and disproportionation is capable of liberating furan and acids [42].

PP was observed to produce a comparatively higher yield of hexadecanoic acid and could be attributed to its higher extractives content. Furthermore, it was noticed that a total of 13 compounds detected in ID were not found in PP. Majority of these compounds were syringyl lignin derivatives. Examples include methyl-syringol, ethyl syringol, 4-vinylsyringol, 2-propenyl syringol, and acetosyringone. A similar observation was made where these compounds were either present only in biomasses of African origin or had a greater yield in comparison with those of European origin [41]. In addition, it was observed that ten compounds with percent area peaks $\geq 1.0 \%$ found in PP were absent in ID. It is noteworthy that 3-hydroxy-1-propenyl-guaiacol, a product of lignin decomposition, had the highest peak (12\%), and it was only detectable in PP. Furthermore, oleic acid (4.1\%) together with resin acids $(2.6 \%)$ were detected in PP. Generally, the lignin-derived compounds identified were more than $60 \%$; this may not be unconnected with the design configuration of the Py-GC/MS unit. The air-tight design facilitates the efficient cleavage of some ether linkages in the lignin components, thus, enhancing the decomposition of lignin leading to a higher conversion in comparison to the conventional pyrolysis units [41].

\section{Conclusion}

The two woody biomass samples from the USA and Nigeria, PP and ID, were successfully characterized for composition, thermal decomposition products, and thermal decomposition kinetics. There were marked differences in the composition of both biomass species as ID showed higher contents of lignin, ash, and $\mathrm{CH}_{2} \mathrm{Cl}_{2}$ extractives. The TGA clearly demonstrated the degradation mechanism for lignocellulosic biomass fractions and the influence of varied heating rates on the thermal degradation process of both samples studied. The data generated also provided information as to their potential uses as feedstocks for pyrolysis.

The spectroscopic study gave valuable information on cellulose crystallinity, essential functional groups, and the lignin syringyl/guaiacyl ratio in the lignocellulosic species. An IR spectrum revealed that PP possessed cellulose with relatively high crystalline cellulose I content. The apparent activation energy was shown to vary significantly as a function of conversion with $\mathrm{E}(\theta)$ varying from 202 to $365 \mathrm{~kJ} \mathrm{~mol}^{-1}$ for ID and 205 to $583 \mathrm{~kJ} \mathrm{~mol}^{-1}$ for PP. The yields of lignin derivatives 
and acids, from analytical Py-GC/MS, were significantly distinctive for both biomass species.

Acknowledgments We would like to acknowledge David Zack and Dr. Liqing Wei for running the TGA experiments and performing compositional analysis.

\section{References}

1. McKendry P (2002) Energy production from biomass (part 1): overview of biomass. Bioresour Technol 83:37-46

2. Timberlake J, Chidumayo E, Sawadogo L (2010) Distribution and characteristics of African dry forests and woodlands. In: Chidumayo EN, Gumbo DJ (eds) The dry forest and woodlands of Africa: managing for products and services. Earthscan, London, pp 11-41

3. Wennerberg S (2004) Plant guide: Ponderosa pine. United States Department of Agriculture, National Resources Conservation Service, Louisiana, pp 1-4

4. Oliver WW, Ryker RA (1990) Pinus ponderosa. In: Silvic of North America: Volume 1 Conifers. Forest Service, United States Department of Agriculture, Agricultural Handbook 654, Washington, DC, pp 413-424

5. Lasode OA, Balogun, AO (2010) Wood wastes generation in Ilorin metropolis: problems, management challenges and prospects. In. Proceedings of the 25th International Conference on Solid Waste Technology and Management, Philadelphia, PA, 14-17 March 2010

6. Rowell RM, Pettersen R, Han JS, Rowell JS, Tshabalala MA (2005) Cell wall chemistry. In: Rowell RM (ed) Handbook of wood chemistry and wood composites. CRC Press, Boca Raton, pp 3574

7. Naik S, Goud VV, Rout PK, Jacobson K, Dalai AK (2010) Characterisation of Canadian biomass for alternative renewable biofuel. Renew Energ 35:1624-1631

8. Alberts 4B, Johnson A, Lewis J, Raff M, Roberts K, Walter P (2002) Molecular biology of the cell. Garland Sci. 1

9. Gaur S, Reed TB (1998) Thermal data for natural synthetic fuels. Marcel Dekker, New York

10. Popescu C-M, Singurel G, Popescu M-C, Vasile C, Argyropoulos DS, Willför S (2009) Vibrational spectroscopy and x-ray diffraction methods to establish the differences between hardwood and softwood. Carbohydr Polym 77:851-857

11. Rosu D, Teaca C, Bodirlau R, Rosu L (2010) FTIR and color change of the modified wood as a result of artificial light irradiation. J Photochem Photobiol B Biol 99:144-149

12. Balogun AO, Lasode OA, Li H, McDonald AG (2015) Fourier transform infrared (FTIR) study and thermal decomposition kinetics of Sorghum bicolour glume and Albizia pedicellaris residues. Waste Biomass Valor 6:109-116

13. Huang A, Zhou Q, Liu J, Fei B, Sun S (2008) Distinction of three wood species by Fourier transform infrared spectroscopy and twodimensional correlation IR spectroscopy. J Molec Struct 883-884: 160-166

14. Lopez-Velaquez MA, Santes V, Balmaseda J, Torres-Garcia E (2013) Pyrolysis of orange waste: a thermo-kinetic study. J Anal Appl Pyrol 99:170-177

15. Balogun AO, Lasode OA, McDonald AG (2014) Devolatilisation kinetics and pyrolytic analyses of Tectona grandis (teak). Bioresour Technol 156:57-62

16. Balogun AO, Lasode OA, McDonald AG (2014) Thermoanalytical and physico-chemical characterization of woody and non-woody biomass from an agro-ecological zone in Nigeria. BioResources 9:5099-5113

17. Green TR, Popa R (2010) A simple assay for monitoring cellulose in paper-spiked soil. J Polym Environ 18:634-637

18. Liyama K, Wallis AFA (1988) An improved acetyl bromide procedure for determining lignin in woods and wood pulps. Wood Sci Technol 22:271-280

19. Shafizadeh F, Degroot WG (1976) Thermal uses and properties of carbohydrates and lignins. Academic, New York

20. Fabiyi JS, McDonald AG (2010) Effect of wood species on property and weathering performance of wood plastic composites. Compos Part A 41:1434-1440

21. Soria AJ, McDonald AG, He BB (2008) Wood solubilization and depolymerization by supercritical methanol. Part 2: analysis of methanol soluble compounds. Holzforschung 62:409-416

22. Kilic A, Niemz P (2012) Extractives in some tropical woods. Eur J Wood Prod 70:79-83

23. Telmo C, Lousada J (2011) The explained variation by lignin and extractive contents on higher heating value of wood. Biomass Bioenerg 35:1663-1667

24. Vassilev SV, Baxter D, Andersen LK, Vassileva CG (2010) An overview of the chemical composition of biomass. Fuel 89:913933

25. Das P, Ganesh A, Wangikar P (2004) Influence of pretreatment for deashing of sugarcane bagasse on pyrolysis products. Biomass Bioenerg 27:445-457

26. Soria JA, McDonald AG (2012) Liquefaction of softwoods and hardwoods in supercritical methanol: a novel approach to bio-oil production. In: Baskar C, Baskar S, Dhillon RS (eds) Biomass conversion: the interface of biotechnology, chemistry and materials science, pp 421-433. Springer, Verlag

27. Colom X, Carrillo F (2002) Crystallinity changes in lyocell and viscose-type fibres by caustic treatment. Euro Polym J 38:22252230

28. Colom X, Carrillo F (2005) Comparative study of wood samples of the northern area of Catalonia by FTIR. J Wood Chem Technol 25: $1-11$

29. Reiniati I, Osman NB, McDonald AG, Laborie M-P (2015) Linear viscoelasticity of hot-pressed hybrid poplar relates to densification and to the in situ molecular parameters of cellulose. Ann For Sci. doi:10.1007/s13595-014-0421-1

30. Akerholm M, Hinterstoisser B, Salmen L (2004) Characterization of the crystalline structure of cellulose using static and dynamic FTIR spectroscopy. Carbohydr Res 339:569-578

31. Yildiz S, Gumuskaya E (2007) The effects of thermal modification on crystalline structure of cellulose in soft and hardwood. Build Environ 42:62-67

32. Carrillo F, Colom X, Sunol JJ, Saurina J (2004) Structural FTIR analysis and thermal characterisation of lyocell and viscose-type fibres. Euro Polym J 40:2229-2234

33. Chen M, McClure JW (2000) Altered lignin composition in phenylalanine ammonia-lyase-inhibited radish seedlings: implications for seed-derived sinapoyl esters as lignin precursors. Phytochemistry 53:365-370

34. Meng L, Kang S, Zhang X, Wu Y, Sun R (2012) Isolation and physicochemical characterization of lignin from hybrid poplar in $\mathrm{DMSO} / \mathrm{LiCl}$ system induced by microwave-assisted irradiation. Cellul Chem Technol 46:409-418

35. Dai J, McDonald AG (2014) Production of fermentable sugars from hybrid poplar: response surface model optimization of a hot-water pretreatment and subsequent enzymatic hydrolysis. Biomass Bioenerg 71:275-284

36. Chen D, Zheng Y, Zhu X (2013) In-depth investigation on the pyrolysis kinetics of raw biomass. Part I: kinetic analysis for the drying and devolatilization stages. Bioresour Technol 131:40-46 
37. Fisher T, Hajaligol M, Waymack B, Kellogg D (2002) Pyrolysis behaviour and kinetics of biomass derived materials. J Anal Appl Pyrol 62:331-349

38. Chen D, Zheng Y, Zhu XF (2012) Determination of effective moisture diffusivity and drying kinetics for poplar sawdust by thermogravimetric analysis under isothermal condition. Bioresour Technol 107:451-455

39. Kim S, Kim J, Park Y-H, Park Y-K (2010) Pyrolysis kinetics and decomposition characteristics of pine trees. Bioresour Technol 101: 9797-9802
40. Yang H, Yan R, Chen H, Zheng C, Lee DH, Liang DT (2006) Indepth investigation of biomass pyrolysis based on three major components: hemicellulose, cellulose and lignin. Energ Fuels 20:388393

41. Azeez AM, Meier D, Odermatt J, Willner T (2010) Fast pyrolysis of African and European lignocellulosic biomasses using Py-GC/MS and fluidized bed reactor. Energ Fuels 24:2078-2085

42. Aho A, Kumar N, Eranen K, Holmbom B, Hupa M, Salmi T, Murzin DY (2008) Pyrolysis of softwood carbohydrates in a fluidized bed reactor. Int J Mol Sci 9:1665-1675 